\title{
Management of post pneumonectomy bronchopleural fistula: the transpericardial approach
}

\author{
Sabyasachi Bal ${ }^{1}$, Kamran Ali ${ }^{1}$, Beena Haridas ${ }^{2}$, Gagan Shrivastava ${ }^{2}$, Sanjay Gupta ${ }^{3}$ \\ ${ }^{1}$ Department of Thoracic Surgery and Thoracic Surgical Oncology, ${ }^{2}$ Department of Anaesthesiology, ${ }^{3}$ Department of Cardiovascular Surgery, Fortis \\ Flt. Lt. Rajan Dhall Hospital, New Delhi, India \\ Correspondence to: Sabyasachi Bal, MS, DNB, FRCS. Department of Thoracic Surgery and Thoracic Surgical Oncology, Fortis Flt. Lt. Rajan Dhall \\ Hospital, New Delhi, India. Email: drsbal@gmail.com.
}

\begin{abstract}
Pneumonectomy is a formidable operation with considerable morbidity and definite mortality of $5-7 \%$. Bronchopleural fistula (BPF) with or without a post-pneumonectomy empyema (PPE) is one of the most dreaded events that can affect the post-operative course following pneumonectomy. It has a prolonged clinical course and the options available for treatment are multiple. There is general agreement that most large fistulae are large and need surgical treatment. This needs a multi-pronged approach. This paper highlights one of the lesser known operations for BPF and underscores its value in difficult clinical situations.
\end{abstract}

Keywords: Pneumonectomy; bronchopleural fistula (BPF); transpericardial; transsternal

Received: 07 September 2018; Accepted: 16 October 2018; Published: 13 November 2018.

doi: $10.21037 /$ jovs.2018.10.18

View this article at: http://dx.doi.org/10.21037/jovs.2018.10.18

\section{Introduction}

Although pneumonectomy for lung cancer has been decreasing in incidence because of technical innovations, the operation continues to be necessary for inflammatory lung diseases and their sequelae. It is a formidable operation with a long list of associate complications (50\%) (1) and a relatively high mortality (5-7\%) amongst lung resections. (1).

One of the most formidable complications is the development of a bronchopleural fistula (BPF) accompanied by an ipsilateral post-pneumonectomy empyema (PPE). Though the latter can occur in isolation (10-20\%) (1). It frequently occurs in conjunction with the former $(60-80 \%)$ (1). The incidence of BPF with PPE in current literature has been reported to occur at the rate of $1.8 \%$ to $28 \%$. The rate of isolated empyemas is $2-16 \%$ (1).

The clinical features and initial management have been the subject of several seminal papers (1-4) and are well known and will not be elaborated further. It is sufficient to say that BPFs range from small to total disruption. The smaller ones may heal spontaneously following intercostals tube thoracostomy and irrigation or by an Eloesser type open window thoracostomy (OWT) with diligent dressings to control the accompanying sepsis. BPFs may occur early, largely due to technical reasons and need urgent surgical intervention (2). The majority however, are chronic and occur 4 weeks to several months (and even years) after the index operation $(1,2)$

It is therefore, important to reiterate the risk or predisposing factors for the development of a BPF and ponder over preventive strategies since the treatment for the established condition is a formidable enterprise.

\section{Risk factors and prevention}

The risk factors contributing to the development of a BPF have been studied by several investigators (3). They can, like all risk factors be attributed to patient related, technical and management related components (Table 1).

\section{Management}

$80 \%$ of empyemas after pneumonectomy are associated with BPFs. Conservative treatment can lead to healing in a small proportion of patients (2) and minimally invasive techniques, including thoracoscopic intervention have been 
Table 1 Risk factors for development of BPF

Patient related
Inflammatory disease
Right pneumonectomy
Low $\mathrm{FEV}_{1}$ and $\mathrm{DL}_{\mathrm{co}}$
Diabetes
Low albumin
Age
Neoadjuvant treatment
Technique or management related
Devascularized or long stump
Tension in stump closure
Positive margins in cancer patients
Stapled versus sutured closure?
Absence of stump reinforcement
Postop mechanical ventilation

BPF, bronchopleural fistula.

shown to be feasible (1). However, most BPFs, especially after surgery for inflammatory disease, are large (5) and need a series of management maneuvers for treatment and cure.

It is imperative to understand that surgical closure of the $\mathrm{BPF}$ is the cornerstone of management and that the associated empyema usually heals following the successful closure of the BPF $(1,5)$.

The principles of BPF and PPE management have recently been the subject of much attention $(1,4)$. Gleanings from these studies are summarized in the algorithm below (Figure 1). Details of the ancillary management as stated in the algorithm are outside the purview of this article but excellent references exist in the literature (1). Hence attention will only be directed to the two surgical techniques, viz. transthoracic and transpericardial approaches to the bronchial closure in a BPF, the latter in greater detail.

\section{Transthoracic approach}

Conventionally, early BPFs (within 5-10 days) are usually approached urgently through the previous thoracotomy incision. The bronchial stump is dissected up to the carina and closed and covered with a muscle flap or omentum.
The chest cavity is managed usually by a modification of the Clagget procedure (2) or by a thoracomyoplastic operation $(6,7)$.

For BPF and PPE occurring later, organization of tissues, fibrosis and associated inflammation often render the transthoracic route hazardous with a risk of bleeding and injury to vital structures $(1,2,5)$. Failure rates are $18-20 \%$ and there is at least a $15 \%$ mortality $(1,2)$. Considering the above, it stands to reason that an approach through healthy, virgin and well vascularized tissue to the carina and bronchi would be preferable. Such an approach is provided by the transsternal transpericardial route.

\section{Transternal transpericardial route}

The classic indications in western literature for TP are summarized (2):

* Inability to access the fistula by the transthoracic route;

* Failed previous transthoracic surgery;

* Patients with very short bronchial stump;

* Necrotic bronchial stump;

- Disease involving carina and bronchial origin.

Most western authors $(1,2)$ have used the transthoracic approach as the primary approach and use the TP route only when the above indications exist. The reason for this is not entirely clear and given the hazards of dissecting the bronchus through an already inflamed operative field, we prefer to use the TP route as the initial approach. Several Russian authors (8) and de la Riviere, in a large series of patients have used the TP technique as the initial procedure of choice (9).

\section{Surgical technique}

Most patients with BPF and PPE have either a tube thoracostomy or OWT in situ. If this is not there, one needs to be made as a mandatory preliminary procedure and wait till reasonable control of sepsis has been obtained. A bronchoscopy is required to assess the length and status of the stump.

One TP has been planned lung isolation needs to be attained. This can be achieved by a variety of techniques (2). Normally a double lumen tube is satisfactory but for short stumps, a long single tube may be inserted into the left main bronchus for a right sided fistula. Use of an endobronchial blocker, packing of the open stump through the OWT or high frequency jet ventilation are good options (2). 


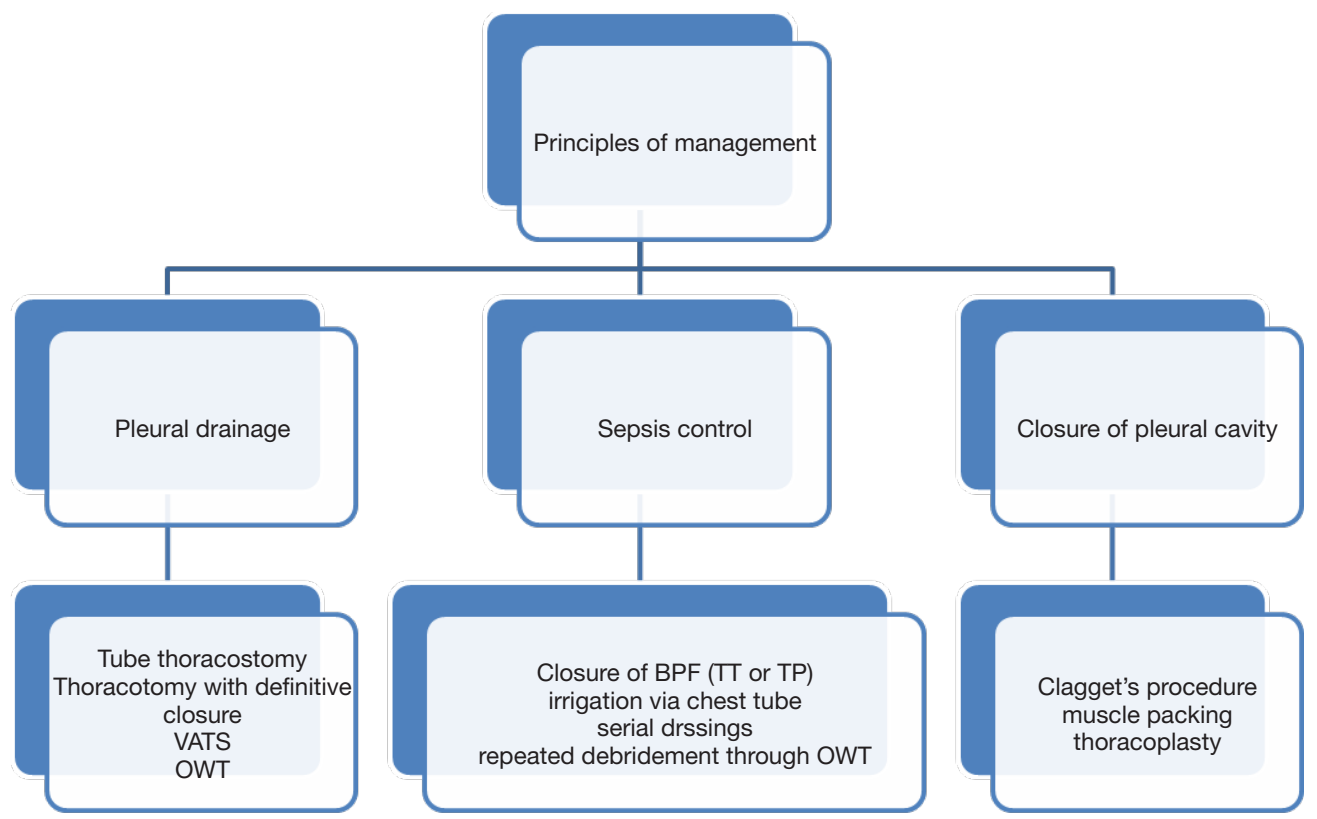

Figure 1 Summary of BPF management. BPF, bronchopleural fistula; OWT, open window thoracostomy; VATS, video-assisted thoracic surgery.

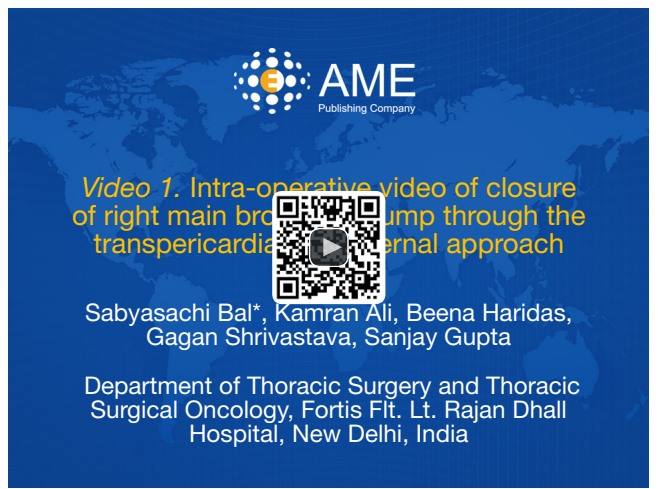

Figure 2 Intra-operative video of closure of right main bronchial stump through the transpericardial transsternal approach (10). Available online: http://www.asvide.com/article/view/28255

A midline sternotomy is made. The superior vena cava and aorta are mobilized and retracted after opening the anterior pericardium. Corrugated rubber drains are useful tools for retraction (Figure 2). Ginsberg (2) advises tracheal mobilization before opening the anterior pericardium but this in our opinion is rarely required. We mobilize the trachea only if carinal resection is deemed necessary.

The pulmonary artery is mobilized and retracted downwards; a reamputation using a vascular stapler

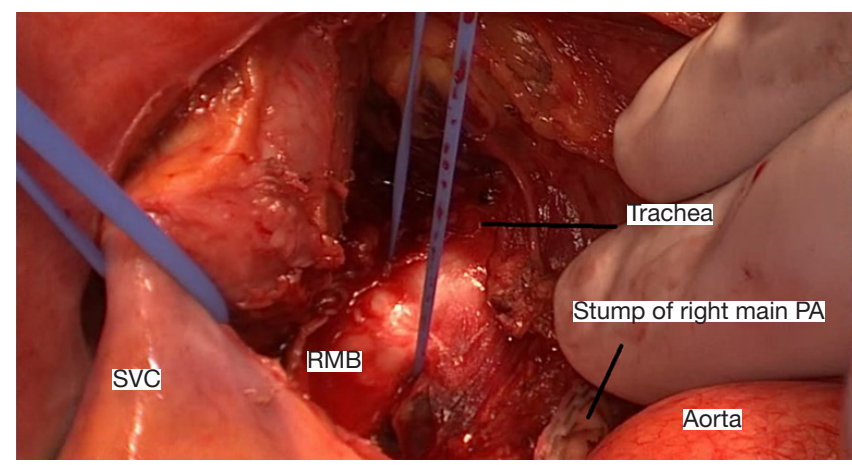

Figure 3 Intra-operative view of important structures after reamputation of right main pulmonary artery. PA, pulmonary artery; SVC, superior vena cava; RMB, right main bronchus.

gives better visualization and should be considered. The posterior pericardium is now incised and the carina and bronchial divisions are visualized and exposed. A blunt finger dissection to mobilize the main bronchus is a useful maneuver. Further sharp and blunt dissection in obtaining additional length of the bronchial stump (Figure 3). This safeguards the esophagus and the recurrent laryngeal nerve. The exposed bronchial stump is then stapled and divided at the carina using a Tri-stapler (Medtronics USA). The proximal stapleline is covered using pericardium or thymic 
Table 2 Collected results in literature

\begin{tabular}{|c|c|c|c|c|c|}
\hline Author & Year & Number & Success rate (\%) & Recurrence (\%) & $30-$ day mortality (\%) \\
\hline de la Reviere (9) & 1997 & 55 & 83 & 17 & 24 \\
\hline Stamatis (12) & 1996 & 19 & 89 & 11 & 5 \\
\hline Ginsberg (2) & 1989 & 13 & 80 & 20 & - \\
\hline Baldwin (14) & 1985 & 10 & 66 & 33 & - \\
\hline Case reports & 2002-2018 & 6 & 100 & - & - \\
\hline Bal et al.* & 2018 & 57 & 96 & 4 & 2 \\
\hline
\end{tabular}

*, under publication.

tissue as advised by Ginsberg. Stapling in continuity is not advisable because of high recurrence rates.

Sometimes, there may be a large mediastinal shift. In these cases the carina and bronchi may be approached by a right anterior thoracotomy or a right parasternal thoracotomy (11) and excision of 2-6th costal cartilages. For the left side, when significant mediastinal shift has occurred, complete mobilisation of the aorta and pulmonary truncus has been advised by Ginsberg (2) to gain access to the left of the aorta. We have no experience of this maneuver.

In case of an extremely short bronchial stump, a carinal resection and tracheobronchial anastomosis is indicated. Table 2 shows the results of seven major series of patients treated by TP. These results suggest that morbidity and mortality can be reduced by good nutrition, control of sepsis with an OWT followed by a definitive procedure where TP remains the operation of choice. Surgery in an emergency situation in unselected patients can lead to a high mortality $(2,9)$ but does not detract from the efficacy of the procedure.

In summary, the major advantages of TP are avoidance of areas of infection, access through virgin anatomy without scarring in previous operative fields, avoidance of vascularity problems in the bronchus, ability to do a tracheobronchial anastomosis and avoidance of cosmetic and functional deformities that may be caused by myoplasty and thoracoplasty. In our opinion it is the procedure of choice in most and certainly when a transthoracic approach is contraindicated, has failed or when resection is required. The major disadvantage of this procedure is that the residual empyema cavity is not dealt with at the same time unlike the transthoracic operation. In our clinical experience and those of other authors (5), sterilization and closure of the pleural space occurs rapidly because contamination of the pleural space from the BPF no longer exists. In case the patient has a tube thoracostomy, this can be irrigated to sterility by irrigation. IN case of an OWT, dressings are continued. Both techniques lead to rapid control of the pleural cavity. The other disadvantage of this procedure is in those who have undergone a sternotomy earlier. Though resternotomies have been reported (1) these are probably avoided and other alternatives chosen for therapy.

Finally it must be understood that this is not an emergency procedure. Reasonable time must be spent in improving nutrition and controlling infection by irrigation through a tube thoracostomy or by an OWT before attempting the bronchial repair.

\section{Acknowledgments}

Funding: None.

\section{Footnote}

Provenance and Peer Review: This article was commissioned by the editorial office, Journal of Visualized Surgery for the series "Asia Thoracoscopic Surgery Education Program (ATEP) Special Issue on Inflammatory Thoracic Diseases". The article has undergone external peer review.

Conflicts of Interest: All authors have completed the ICMJE uniform disclosure form (available at http:// dx.doi.org/10.21037/jovs.2018.10.18). The series "Asia Thoracoscopic Surgery Education Program (ATEP) Special Issue on Inflammatory Thoracic Diseases" was commissioned by the editorial office without any funding 
or sponsorship. KA served as the unpaid Guest Editor of the series. The authors have no other conflicts of interest to declare.

Ethical Statement: The authors are accountable for all aspects of the work in ensuring that questions related to the accuracy or integrity of any part of the work are appropriately investigated and resolved. All procedures performed in studies involving human participants were in accordance with the ethical standards of the institutional and/or national research committee(s) and with the Helsinki Declaration (as revised in 2013). Written informed consent was obtained from the patient for publication of this manuscript and any accompanying images.

Open Access Statement: This is an Open Access article distributed in accordance with the Creative Commons Attribution-NonCommercial-NoDerivs 4.0 International License (CC BY-NC-ND 4.0), which permits the noncommercial replication and distribution of the article with the strict proviso that no changes or edits are made and the original work is properly cited (including links to both the formal publication through the relevant DOI and the license). See: https://creativecommons.org/licenses/by-nc-nd/4.0/.

\section{References}

1. Bribriesco A, Patterson GA. Management of post pneumonectomy bronchopleural fistula; from thoracoplasty to transsternal closure. Thorac Surg Clin 2018;28:323-35.

2. Ginsberg RJ, Pearson FG, Coooper JD et al. Closure of chronic post pneumonectomy bronchopleural fistula using transsternal transpericardial approach. Ann Thorac Surg 1989;47:231-5.

3. Pettiford BL, Luketich JD, Landreaneau RJ. Surgical approaches for chronic empyema and for management of chronic bronchopleural fistula. In: Sugarbaker DJ, Bueno R, Krasna MJ, et al. editors. Adult Thoracic Surgery. 1st Edition. Mcgraw-Hill Medical, 2009:475-85.

doi: $10.21037 /$ jovs.2018.10.18

Cite this article as: Bal S, Ali K, Haridas B, Shrivastava G, Gupta S. Management of post pneumonectomy bronchopleural fistula: the transpericardial approach. J Vis Surg 2018;4:237.
4. Ginsberg RJ, Sabrio DV. Management of recalcitrant postpneumonectomy bronchopleural fistula the transternal transpericardial approach. Semin Thorac Cardiovasc Surg 2001;13:20-6.

5. Topcuoglu MS, Kayhan C, Ulius T. Tanssternal approach for the repair of bronchopleural fistula with empyema. Ann Thorac Surg 2000;69:394-7.

6. Pairolero PC, Arnold PG, Pihler JM. Intrathoracic transposition of extrathoracic skeletal muscle. J Thorac Cardiovasc Surg 1983;86:809-17.

7. García-Yuste M, Ramos G, Duque JL, et al. Open-window thoracostomy and thoracomyoplasty to manage chronic pleural empyema. Ann Thorac Surg 1998;65:818-22.

8. Perelman MI, Rymko LP, Ambatiello GP. Bronchopleural fistula: surgery after pneumonectomy. In: Grillo H, Eschapasse H. editors. International Trends in Thoracic Surgery (vol 2). Philadelphia, WB Saunders, 1987:407-12.

9. de la Riviere AB, Defaw JJ, Knaepen PJ, et al. Transsternal closure of bronchopleural fistula after pneumonectomy. Ann Thorac Surg 1997;64:954-7; discussion 958-9.

10. Bal S, Ali K, Haridas B, et al. Intra-operative video of closure of right main bronchial stump through the transpericardial transsternal approach. Asvide 2018;5:855. Available online: http://www.asvide.com/article/ view/28255

11. Morimoto K, Taniguchi I, Nakamura Y, et al. Transpericardial operation in the treatment of chronic empyema with bronchopleural fistula. Jpn J Thorac Cardiovasc Surg 2002;50:246-8.

12. Stamatis G, Martini G, Freitag L, et al. Transternal transpericardial operations in the treatment of bronchopleural fistula after pneumonectomy. Eur J Cardiothorac Surg 1996;10:83-6.

13. Beltrami V. Surgical transternal treatment of bronchopleural fistula after pneumonectomy. Chest 1989;95:379-82.

14. Baldwin JC, Mark JBD. Treatment of bronchopleural fistula after pneumonectomy. J Thorac Cardiovasc Surg 1985;90:813-7. 